\title{
An international comparison of productivity change in the textile and clothing industry: a bootstrapped Malmquist index approach
}

\author{
Magdalena Kapelko • Alfons Oude Lansink
}

Received: 27 November 2012 / Accepted: 15 April 2014 / Published online: 23 July 2014

C The Author(s) 2014. This article is published with open access at Springerlink.com

\begin{abstract}
Firms in the textile and clothing industry operate in competitive international markets characterized by the liberalized trade after the removal of multi-fiber agreement quotas in 2005, and have to address rapid changes in consumer preferences and production technology. Hence, improving competitiveness is crucial for firm survival. Competitiveness of the sector often depends on its firms meeting their production potential. This paper analyzes productivity changes in the textile and clothing industry worldwide during the period 1995-2004. A bootstrapped Malmquist approach is used to identify the respective contributions of technical change, technical efficiency change, and scale efficiency change. Moreover, differences in productivity changes across different groups of firms are statistically assessed. Our results show a relatively small overall productivity increase for both textile and clothing firms due to positive technical change, despite declines in technical and scale efficiency. Furthermore, our results indicate that productivity and its components differ for textile firms and clothing firms, for firms in countries that benefited and did not benefit from the quotas' elimination, and for firms in different regions.
\end{abstract}

Keywords Data envelopment analysis - Malmquist index · Bootstrap - Textile . Clothing industry

M. Kapelko $(\varangle)$

Department of Logistics, Institute of Applied Mathematics, Wroclaw University of Economics, ul. Komandorska 118/120, 53-345 Wroclaw, Poland

e-mail: magdalena.kapelko@ue.wroc.pl

A. Oude Lansink

Business Economics Group, Wageningen University, Hollandseweg 1,

6706 KN Wageningen, Netherlands

e-mail: Alfons.OudeLansink@wur.nl 
JEL Classification $\quad \mathrm{C} 61 \cdot \mathrm{D} 24 \cdot \mathrm{L} 67 \cdot \mathrm{O} 33 \cdot \mathrm{P} 52$

\section{Introduction}

The textile and clothing industry is facing great challenges due to its highly competitive nature and the ongoing globalization and internationalization of the textile and clothing markets. For over 30 years, trade relations in the textile and clothing sector were dominated by the multi-fiber agreement (MFA). The agreement played a crucial role in protecting producers from the developed world against competition from developing countries by allowing countries to impose quotas on imports of different categories of textile and clothing products. During the Uruguay Round, it was agreed to remove the quotas progressively over a 10-year period until 2005. Additionally, firms in the textile and clothing industry face rapid changes in production technology and consumer preferences toward more variety, higher quality, and more fashionable products (Owen 2001; Stengg 2001). Over the last two decades, the sector restructured and modernized its production, resulting in a large number of firm exits in the industry and a reduction of the industry's workforce by more than $40 \%$ in Europe and approximately $30 \%$ in the USA. In addition, the Asian textile and clothing industry was restructuring and making considerable adjustments to reduce employment, return to profitability, decrease the number of firms, and increase efficiency (Yeung and Mok 2004). Although the trends of decreasing employment and number of firms are expected to continue in the international textile and clothing industry, the industry remains a relatively important sector of the economies of many developed and developing countries. In 2004, the US textile and clothing industry accounted for $8 \%$ of the nation's total value added in manufacturing; in Japan, China, and Italy, the industry accounted for more than 9, 11 and over $11 \%$ of total manufacturing value added, respectively (World Bank 2005).

Pressures related to technological change and internationalization have affected the textile and clothing industry in recent decades, which has considerably altered the environment in which firms operate. The globalization and liberalization of markets increases competition, which could force firms to operate more efficiently in order to survive. In addition, the expanded set of customer tastes could imply that firms need to modify their technologies to produce new goods. While these changes might result in technical progress, they do not necessarily increase technical efficiency or productivity, especially when firms improve the quality of output to meet market demand for variety and fashion. In addition, the new environment of the textile and clothing industry can privilege some of the sub-sectors while disadvantaging others; this disparity could result in differences in efficiency or technical change between the textile and clothing industries. The manufacturing of clothing is largely low-tech and labor-intensive, while the textile industry is more technology-intensive and requires less unskilled labor (Mittelhauser 1997; Datta and Christoffersen 2005). However, the clothing sector also has a segment of high-quality fashion characterized by the use of modern technology. Furthermore, the textile industry is less flexible in terms of adjusting to consumer tastes than clothing (Nordås 2004). Finally, at the firm level, the contributions of efficiency, scale, and technical change depend on the firm's regional location due to the region-specific characteristics of this industry. 
Although productivity growth is essential for survival of textile and clothing firms that operate in international markets and in a dynamic environment, it is unclear what causes productivity growth. Existing studies analyzing the evolution of productivity of textile and clothing companies have used both parametric (e.g., Stochastic production frontier) and nonparametric (e.g., Data Envelopment Analysis) approaches. Previous studies have focused on the analysis of the textile and clothing industry in individual countries. Datta and Christoffersen (2005) focused on the USA and found productivity growth of $2.1 \%$ that was mainly driven by technical change. Wadud (2007) analyzed Australian textile and clothing firms over the period 1995-1998 and found both years with productivity decline and years with productivity increases. Goaïed and Ayed-Mouelhi (2000) and Ayed-Mouelhi and Goaïed (2003) focused on Tunisia; they found both technical regress and technical progress, depending on the method applied. Several studies focused on countries in Asia, such as Leung (1998), Färe et al. (2001), and Chen (2003), who found high productivity growth rates of 7, 6, and $9 \%$ for Singapore, Taiwan, and China, respectively. In all cases, productivity growth was mainly driven by technical change. Lower productivity growth rates were found by Mahadevan (2002) for Malaysia (0.3\%) and by Joshi and Singh (2010) for India (1.7\%). Margono and Sharma (2006) and Kong et al. (1999) reported productivity declines in Indonesia and China, respectively. Goncharuk (2007) found a large productivity decline of $7.29 \%$ for Ukraine. Taymaz and Saatçi (1997) found rapid technical progress $(6 \%)$ for Turkish textile and clothing firms.

Previous studies analyzing productivity change in the textile and clothing industry have generally focused on a specific country and do not assess the differences across countries/regions. An international comparison of productivity change within this sector has not been made thus far. A systematic study that compares the evolution of productivity over time for textile and clothing firms across several countries/regions worldwide is fundamentally important for assessing the competitiveness of this sector in the globalized market.

Given this background, the objective of this paper is to analyze productivity changes of firms in the textile and clothing industry. The empirical application focuses on panel data over the period 1995-2004 of larger stock exchange listed firms in the textile and clothing industry in Asia, Europe, North America, Middle and South America, and the Rest of the World. The time period considered in this study covers the period of increasing trade liberalization in the textile and clothing industry when MFA quotas were gradually removed. We use the Malmquist index and follow Ray and Desli (1997) to decompose productivity growth to identify the respective contributions of technical efficiency change, scale efficiency change, and technical change. Unlike previous studies of the textile and clothing sector, our research undertakes a worldwide analysis of the textile and clothing sector and accounts specifically for scale efficiency change. Furthermore, our study applies the bootstrap method for computing the Malmquist index to obtain statistical inference. The bootstrap approach used in this study extends that of Simar and Wilson (1999) by implementing the Ray and Desli (1997) decomposition of productivity growth.

The remainder of this paper is organized as follows. Section 2 elaborates on the bootstrapped Malmquist approach and its decomposition. This is followed by the 
presentation of the data (Sect. 3) and discussion of results (Sect. 4). The final section offers concluding comments.

\section{Methodology}

In this section, we present the input-oriented Malmquist index and its decomposition. The input orientation in the Malmquist index is appropriate for the textile and clothing industry as this sector is embedded in a competitive market, where outputs are defined by demand and limited only by the utilization of the available resources. The input-oriented Malmquist index is based on the input distance function introduced by Shephard (1970). The production technology of a firm producing output $y^{t}$ and using input $x^{t}$ is represented by the production set

$$
T^{t}=\left\{\left(\mathbf{x}^{t}, \mathbf{y}^{t}\right): \mathbf{x}^{t} \text { can produce } \mathbf{y}^{t}\right\}
$$

and the input sets:

$$
L\left(\mathbf{y}^{t}\right)=\left\{\mathbf{x}^{t}:\left(\mathbf{x}^{t}, \mathbf{y}^{t}\right) \text { is feasible }\right\}
$$

The input distance function for period $t$ is defined as follows:

$$
D^{t}\left(\mathbf{x}^{t}, \mathbf{y}^{t}\right)=\max \left\{\lambda:\left(\mathbf{x}^{t} / \lambda\right) \in L\left(\mathbf{y}^{t}\right)\right\}
$$

where $\lambda$ is the value of the input distance function. Using $t+1$ instead of $t$ in (3), one can obtain $D^{t+1}\left(\mathbf{x}^{t+1}, \mathbf{y}^{t+1}\right)$. In addition to these two distance functions, the computation of Malmquist requires the formulation of two mixed period distance functions. One concerns the firm at time $t+1$ in relation to the technology at $t$

$$
D^{t}\left(\mathbf{x}^{t+1}, \mathbf{y}^{t+1}\right)=\max \left\{\lambda:\left(\mathbf{x}^{t+1} / \lambda\right) \in L\left(\mathbf{y}^{t}\right)\right\}
$$

The second refers to the firm at time $t$ in relation to the technology at $t+$ $1 D^{t+1}\left(\mathbf{x}^{t}, \mathbf{y}^{t}\right)$, which can be obtained by simply swapping the superscript on $D$ with those of $\mathbf{x}$ and $\mathbf{y}$ in (4).

Assuming constant returns to scale (CRS, indicated with the subscript C), Färe et al. (1992) define an input-oriented Malmquist index between time period $t$ and $t+1$ as $^{1}$ :

$$
M\left(\mathbf{x}^{t}, \mathbf{y}^{t}, \mathbf{x}^{t+1}, \mathbf{y}^{t+1}\right)=\left[\frac{D_{C}^{t}\left(\mathbf{x}^{t+1}, \mathbf{y}^{t+1}\right)}{D_{C}^{t}\left(\mathbf{x}^{t}, \mathbf{y}^{t}\right)} \cdot \frac{D_{C}^{t+1}\left(\mathbf{x}^{t+1}, \mathbf{y}^{t+1}\right)}{D_{C}^{t+1}\left(\mathbf{x}^{t}, \mathbf{y}^{t}\right)}\right]^{\frac{1}{2}}
$$

\footnotetext{
${ }^{1}$ It is worth pointing out that the geometric mean version of the adjacent Malmquist productivity index, which we apply in this paper, does not satisfy the circularity test. The seriousness of the failure to satisfy this test has not been resolved in the literature (Fried et al. 2008). A weaker version of time-neutrality of technical change is necessary and sufficient for this property to hold. For details, see Pastor and Lovell (2007).
} 
Values of the Malmquist input-oriented index that are less than 1 indicate improvements in productivity in period $t+1$ compared to period $t$, whereas values greater than 1 indicate decreases in productivity in period $t+1$ compared to period $t$. Although one well-known pitfall of the Malmquist index is that it only measures a local technical change and does not have the total factor productivity (TFP) interpretation (see O'Donnell (2010) for more details), it is widely applied in empirical research for measuring productivity growth in a variety of industrial sectors.

The literature proposes different decompositions of the Malmquist index. The most commonly used decompositions are the formulations proposed by Färe et al. (1992) and Färe et al. (1994). Färe et al. (1992) decomposes the Malmquist index to identify two sources of productivity change: technical efficiency change and technical change. Technical efficiency change reflects the movement of a firm toward the CRS frontier (technical efficiency increase) or away from the CRS frontier (technical efficiency decrease). Technical change measures the shift of the CRS frontier itself from one period to the next. Färe et al. (1994) further decompose the efficiency change index into two indexes: one that measures the change in efficiency with respect to the variable returns to scale (VRS) technology and one that assesses the scale efficiency change, which is the comparison of the distance function gauged relative to the CRS with that relative to the VRS technology. However, the CRS assumption in the technical change component in this formulation is problematic: the estimation of the technology would be statistically inconsistent if the underlying true technology does not exhibit CRS. Hence, it is useful to estimate the changes in technology by the changes in the VRS frontier, as proposed by Ray and Desli (1997). Whereas the Ray and Desli formulation is widely supported in the literature ${ }^{2}$, its empirical application is limited (examples of its usage include Kumar and Basu 2008; Guan and Chen 2010; and Mahlberg and Url 2010). Ray and Desli (1997) break down the Malmquist index into three sources of productivity change:

$$
\begin{gathered}
M\left(\mathbf{x}^{t}, \mathbf{y}^{t}, \mathbf{x}^{t+1}, \mathbf{y}^{t+1}\right)=\left(\frac{D_{V}^{t+1}\left(\mathbf{x}^{t+1}, \mathbf{y}^{t+1}\right)}{D_{V}^{t}\left(\mathbf{x}^{t}, \mathbf{y}^{t}\right)}\right) \cdot\left[\frac{D_{V}^{t}\left(\mathbf{x}^{t+1}, \mathbf{y}^{t+1}\right)}{D_{V}^{t+1}\left(\mathbf{x}^{t+1}, \mathbf{y}^{t+1}\right)} \cdot \frac{D_{V}^{t}\left(\mathbf{x}^{t}, \mathbf{y}^{t}\right)}{D_{V}^{t+1}\left(\mathbf{x}^{t}, \mathbf{y}^{t}\right)}\right]^{\frac{1}{2}} . \\
\text { techniciencyl change change }
\end{gathered}
$$

Note that the subscript $V$ refers to the VRS technology. Scale efficiency change is the product of scale efficiency as in Färe et al. (1994) and the ratio of technical change and technical change itself under CRS and VRS technologies, respectively. The technical change component is the geometric mean of two ratios of VRS distance functions reflecting period $t$ and period $t+1$ technologies. The first ratio measures technical

\footnotetext{
2 Among many authors supporting this decomposition is Lovell (2003). In the single output case, this proposal coincides with the decompositions of Grifell-Tatjé and Lovell (1999), Balk (2001) and Lovell (2003) (Zofio 2007).
} 
change as the ratio computed using period $t+1$ quantities; the second ratio is computed using period $t$ quantities. The technical change component represents the productivity change that can be attributed to a movement in the VRS frontier between two time periods. If any of these components is smaller than 1, then a firm has improved its technical efficiency, scale efficiency, or technology; components equal to 1 suggest no change; and components larger than 1 suggest a decrease in technical efficiency, scale efficiency, or technology.

It is worth pointing out that one could also consider applying the formulations and decompositions of Malmquist index that control for capital fixity. Such an approach could be appropriate for the technology-intensive textile industry that is characterized by a large share of fixed inputs that cannot be adjusted rapidly. However, our database concerns firms in regions across the world, and the textile industry is more capital intensive in e.g., North America and Europe, but less capital intensive in Asia. Therefore, the capital fixity assumption could be more suitable for textile firms in North America and Europe and less for Asia. In order to be consistent across the entire dataset of textile firms and due to the limitation of data as it is not possible to do the separate estimations for every region, the issue of correcting for input fixity is left for future work.

We calculate the component distance functions of the Malmquist index using the linear programming technique known as Data Envelopment Analysis (DEA) (Charnes et al. 1978; Banker et al. 1984). The Malmquist computation requires solving eight linear programs for each decision making unit $i\left(\mathrm{DMU}_{\mathrm{i}}\right)$ : four single-period (under VRS and CRS) and four mixed period distance functions (under VRS and CRS). Assume $k$ DMUs, each of which uses $N$ inputs $\left(x_{n i}^{t}\right)$ to produce $M$ outputs $\left(y_{m i}^{t}\right)$. The distance function $D_{C}^{t}\left(\mathbf{x}^{t}, \mathbf{y}^{t}\right)$ is calculated by solving the following linear program:

$$
\begin{array}{ll}
{\left[D_{C}^{t}\left(\mathbf{x}^{t}, \mathbf{y}^{t}\right)\right]^{-1}} & =\operatorname{Min} \lambda \\
\text { subject to } & y_{m 0}^{t} \leq \sum_{i=1}^{k} z_{i} y_{m i}^{t}, \quad m=1, \ldots, M \\
& \lambda \cdot x_{n 0}^{t} \geq \sum_{i=1}^{k} z_{i} x_{n i}^{t}, \quad n=1, \ldots, N \\
& z_{i} \geq 0 .
\end{array}
$$

In this program, $z_{i}$ reflects the activity levels associated with inputs and outputs of $\mathrm{DMU}_{\mathrm{i}}$ used to construct the linear segments of the CRS frontier. Note that $D_{C}^{t+1}\left(\mathbf{x}^{t+1}, \mathbf{y}^{t+1}\right)$ is obtained using the analogous program. The mixed period distance function $D_{C}^{t}\left(\mathbf{x}^{t+1}, \mathbf{y}^{t+1}\right)$, which projects quantities in period $t+1$ on the production frontier from period $t$, is given by:

$$
\begin{array}{ll}
{\left[D_{C}^{t}\left(\mathbf{x}^{t+1}, \mathbf{y}^{t+1}\right)\right]^{-1}} & =\operatorname{Min} \lambda \\
\text { subject to } & y_{m 0}^{t} \leq \sum_{i=1}^{k} z_{i} y_{m i}^{t+1}, \quad m=1, \ldots, M \\
& \lambda \cdot x_{n 0}^{t} \geq \sum_{i=1}^{k} z_{i} x_{n i}^{t+1}, \quad n=1, \ldots, N \\
& z_{i} \geq 0 .
\end{array}
$$


Again, the mixed period distance function $D_{C}^{t+1}\left(\mathbf{x}^{t}, \mathbf{y}^{t}\right)$, which projects quantities in period $t$ on the production frontier in period $t+1$, is obtained analogously. Adding the restriction $\sum_{i=1}^{k} z_{i}=1$ to the linear program in (7) or (8) gives the distance function under the VRS technology.

To perform statistical inference for the Malmquist index and its components, bootstrap techniques can be used. Bootstrapping is defined as a repeated simulation of the data-generating process achieved by resampling from the data and applying the original estimator to each simulated sample; resulting estimates imitate the original unknown sampling distribution of the estimators of interest. We follow Simar and Wilson's (Simar and Wilson 1999, 2000) algorithm adapted for the Ray and Desli (1997) decomposition. Although the bootstrap has been applied to the Malmquist index before (e.g., Gitto and Mancuso 2012), it has so far been rarely applied to the decomposition of the Malmquist index proposed by Ray and Desli (1997). The algorithm is summarized in the following steps:

1) From the original data set, compute the distance functions composing the Malmquist index $\hat{M}_{i}\left(\mathbf{x}^{t}, \mathbf{y}^{t}, \mathbf{x}^{t+1}, \mathbf{y}^{t+1}\right)$ and its components $\hat{E}_{i}\left(\mathbf{x}^{t}, \mathbf{y}^{t}, \mathbf{x}^{t+1}, \mathbf{y}^{t+1}\right)$, $\hat{S}_{i}\left(\mathbf{x}^{t}, \mathbf{y}^{t}, \mathbf{x}^{t+1}, \mathbf{y}^{t+1}\right)$, and $\hat{T}_{i}\left(\mathbf{x}^{t}, \mathbf{y}^{t}, \mathbf{x}^{t+1}, \mathbf{y}^{t+1}\right)$ for each DMU $i=1, \ldots, k$ by solving the linear programming model (7) and its variations for $t+1$, mixed period and VRS distance functions.

2) Use a smoothed bootstrap to generate a pseudo-dataset $\left\{\left(\mathbf{x}_{i}^{t^{*}}, \mathbf{y}_{i}^{t^{*}}, \mathbf{x}_{i}^{t+1^{*}}, \mathbf{y}_{i}^{t+1^{*}}\right.\right.$, $i=1, \ldots, k\}$ by drawing with replacement from the joint density of original distance functions. This density is estimated using a bivariate kernel density and univariate reflection method adapted to the bivariate case; this approach accounts for the possible temporal correlation arising from the time series dimension of the panel data. When the joint density is already estimated, drawing a pseudo-sample involves solving the additional linear programs. For observations for which one of the linear programs gives infeasible solutions, the bootstrap values are deleted and the procedure of drawing with replacement is repeated ${ }^{3}$.

3) Construct the bootstrap estimates of distance functions that compose the Malmquist index and its decomposition indices for each DMU $i=1, \ldots, k$ by applying the original estimators to the pseudo-dataset derived from step 2 . Use these estimates to compute bootstrap estimates of the Malmquist index and its components for each DMU $i=1, \ldots, k$, yielding $\hat{M}_{i b}^{*}\left(\mathbf{x}^{t}, \mathbf{y}^{t}, \mathbf{x}^{t+1}, \mathbf{y}^{t+1}\right)$, $\hat{E}_{i b}^{*}\left(\mathbf{x}^{t}, \mathbf{y}^{t}, \mathbf{x}^{t+1}, \mathbf{y}^{t+1}\right), \hat{S}_{i b}^{*}\left(\mathbf{x}^{t}, \mathbf{y}^{t}, \mathbf{x}^{t+1}, \mathbf{y}^{t+1}\right)$ and $\hat{T}_{i b}^{*}\left(\mathbf{x}^{t}, \mathbf{y}^{t}, \mathbf{x}^{t+1}, \mathbf{y}^{t+1}\right)$.

\footnotetext{
3 We could refer to this infeasibility as bootstrap infeasibility, which occurs when the observation lies above the bootstrap sample of a frontier (Simar and Wilson 2000). Another type of infeasibility refers to the infeasibility of the mixed period distance functions. This type of infeasibility occurs more often when an observation is compared with a previous period technology and is not connected with the bootstrap procedure, although the bootstrap procedure can increase its likelihood. Consequently, for such infeasible observations confidence intervals are not calculated, what is explained later in this paper. Therefore, the final infeasibilities reported refer only to the infeasibilities of mixed period distance functions.
} 
4) Repeat steps 2 and $3 B$ times to obtain a set of estimates:

$$
\begin{aligned}
& \left\{\hat{M}_{i 1}^{*}\left(\mathbf{x}^{t}, \mathbf{y}^{t}, \mathbf{x}^{t+1}, \mathbf{y}^{t+1}\right), \ldots, \hat{M}_{i B}^{*}\left(\mathbf{x}^{t}, \mathbf{y}^{t}, \mathbf{x}^{t+1}, \mathbf{y}^{t+1}\right)\right\}, \\
& \left\{\hat{E}_{i 1}^{*}\left(\mathbf{x}^{t}, \mathbf{y}^{t}, \mathbf{x}^{t+1}, \mathbf{y}^{t+1}\right), \ldots, \hat{E}_{i B}^{*}\left(\mathbf{x}^{t}, \mathbf{y}^{t}, \mathbf{x}^{t+1}, \mathbf{y}^{t+1}\right)\right\}, \\
& \left\{\hat{S}_{i 1}^{*}\left(\mathbf{x}^{t}, \mathbf{y}^{t}, \mathbf{x}^{t+1}, \mathbf{y}^{t+1}\right), \ldots, \hat{S}_{i B}^{*}\left(\mathbf{x}^{t}, \mathbf{y}^{t}, \mathbf{x}^{t+1}, \mathbf{y}^{t+1}\right)\right\}, \\
& \left\{\hat{T}_{i 1}^{*}\left(\mathbf{x}^{t}, \mathbf{y}^{t}, \mathbf{x}^{t+1}, \mathbf{y}^{t+1}\right), \ldots, \hat{T}_{i B}^{*}\left(\mathbf{x}^{t}, \mathbf{y}^{t}, \mathbf{x}^{t+1}, \mathbf{y}^{t+1}\right)\right\} .
\end{aligned}
$$

There are two complementary ways of performing the statistical inference on computed indices: estimating bias-corrected indices or estimating confidence intervals. In this paper, we compute the confidence intervals because the bias-corrected estimator may be less reliable when it has a higher standard deviation than the original estimator (Simar and Wilson 1999). The confidence intervals for the Malmquist index are calculated by sorting the values $\hat{M}_{i b}^{*}\left(\mathbf{x}^{t}, \mathbf{y}^{t}, \mathbf{x}^{t+1}, \mathbf{y}^{t+1}\right)-\hat{M}_{i}\left(\mathbf{x}^{t}, \mathbf{y}^{t}, \mathbf{x}^{t+1}, \mathbf{y}^{t+1}\right)$ for $b=1, \ldots, B$ and deleting $\left(\frac{\alpha}{2} \times 100\right)$ - percent of the elements at either end of this sorted array. Then, we set $-\hat{b}_{\alpha}^{*}$ and $-\hat{a}_{\alpha}^{*}\left(\hat{a}_{\alpha}^{*} \leq \hat{b}_{\alpha}^{*}\right)$ equal to the endpoints of the resulting array. As a result, the estimated $(1-\alpha)$ - percent confidence interval is formulated as follows:

$$
\begin{aligned}
& \hat{M}_{i}\left(\mathbf{x}^{t}, \mathbf{y}^{t}, \mathbf{x}^{t+1}, \mathbf{y}^{t+1}\right)+a_{\alpha}^{*} \leq M_{i}\left(\mathbf{x}^{t}, \mathbf{y}^{t}, \mathbf{x}^{t+1}, \mathbf{y}^{t+1}\right) \\
& \quad \leq \hat{M}_{i}\left(\mathbf{x}^{t}, \mathbf{y}^{t}, \mathbf{x}^{t+1}, \mathbf{y}^{t+1}\right)+b_{\alpha}^{*}
\end{aligned}
$$

The same procedure applies to the estimation of the confidence intervals for technical efficiency change, technical change, and scale efficiency change. It should be noted though that confidence intervals are calculated only for observations for which the Malmquist index is well defined, i.e., observations for which all distance functions have feasible outcomes. Therefore, when an infeasibility of mixed period distance functions occurs, the confidence intervals for such observations are not calculated. The interpretation of the confidence intervals is as follows: the Malmquist index for the $i$ th DMU is significantly different from 1 at the 1, 5, or $10 \%$ level if the 99, 95, and $90 \%$ interval in (9) does not include 1. In this paper, the Malmquist index and its decomposition are estimated using FEAR 1.1 package $^{4}$ using $B=2000$ bootstrap replications.

\section{Data}

This study uses the database of publicly traded firms in the international textile and clothing industry. This database combines information collected from three sources: COMPUSTAT, DATASTREAM, and OSIRIS. Although three different sources are used, the consistency of the database is guaranteed, because we use publicly available accounting data that are highly harmonized across countries and the information is

$\overline{4}$ FEAR is freely available software for frontier efficiency analysis with R. It is written by Wilson (2008). 
audited for most firms. Linking these databases is undertaken using the international codes that identify listed firms such as ISIN (International Securities Identifying Number) and SEDOL (Stock Exchange Daily Official List). In addition, firms are classified as either 'textile firms,' or 'clothing firms.' COMPUSTAT and OSIRIS already divide the companies into these categories: COMPUSTAT uses a classification similar to the SIC code ${ }^{5}$, while OSIRIS is based on the NACE Rev. 2 code $^{6}$. In DATASTREAM, all firms fall into one general category of "Clothing and accessories," following the ICB classification ${ }^{7}$. The classification by either textile or clothing industry is obtained using the extended business description provided by DATASTREAM or the firms' webpages. We extracted the firm's balance sheet and profit and loss account from the databases.

Initially, 2,588 firms are extracted from three databases, which are matched such that overlapping observations are removed. This results in a sample of 1,693 firms. After deleting observations with missing information on variables that are necessary to compute Malmquist index, the sample further reduces to 1,064 firms (5,337 observations). Finally, after removing the outliers ${ }^{8}$, the final sample consists of 1,016 textile and clothing firms that operated at least two consecutive years during the period from 1995 to 2004 . The panel is unbalanced and it sums up to 4,985 observations. The firms in the sample are generally larger firms that are listed on the stock exchange and whose main activity is textile and clothing manufacturing. Our sample is almost equally distributed between textile and clothing firms: 2,584 observations are from the clothing industry and 2,401 are from the textile industry. The data come from 39 countries in Asia, Europe, North America, Middle and South America, and the Rest of the World (Australia, Oceania, and Africa). Table 1 provides details of the geographic location and the activity profile (textile or clothing) of the companies included in the sample, along with the information on the number of outliers removed. As it can be appreciated from the table the outliers account for $6.6 \%$ of the initial sample.

\footnotetext{
5 SIC (Standard Industrial Classification) is a number that identifies a company's primary business. In COMPUSTAT number 2290 represents "Apparel and Accessories," while number 2500 refers to "Textiles."

6 NACE Rev. 2 is the European Union classification of economic activities. According to this code, number 13 represents "Manufacture of textiles," while number 14 refers to "Manufacture of wearing apparel."

7 ICB (Industry Classification Benchmark) is a classification standard for trading and investment decisions. The category of "Clothing and accessories" (3763) falls under Consumer Goods (3000)_Personal and Household goods (3700)—Personal goods (3760).

8 It is common knowledge that the DEA is very sensitive to the presence of outliers in the sample (Timmer 1971) and one might be concerned that firms display extreme behavior in the input-output proportions that they use. For the purpose of the paper we want to reduce the number of infeasibilities of the Malmquist index, therefore, we choose the outlier detection method that results in the smallest number of infeasibilities, but may have less proven qualities as an outlier detection method compared to other methods. In this way, we eliminate the firms which may or may not be outliers. Initially, the outliers are determined using the method of Wilson (1993). However, it proves insufficient for us, since after removing outliers we could not get feasible solutions for the Malmquist index for approximately $50 \%$ of sample observations. Therefore, we switch to another method which is frequently applied in the literature in which the outliers are determined using ratios of output to input: an observation is defined as an outlier if the ratio of output over any of the three inputs is outside the interval of the median plus and minus three times the interquartile range. There are also alternative methods of outliers' detection; these include, for example, the methods proposed by Simar (2003) or Ondrich and Ruggiero (2002).
} 
Table 1 Sample characteristics: number of observations for the 1995-2004 time period (outliers are in parentheses)

\begin{tabular}{|c|c|c|c|}
\hline Location & Textile & Clothing & Total \\
\hline Australia & $2(1)$ & $18(2)$ & $20(3)$ \\
\hline Austria & $10(2)$ & $9(0)$ & $19(2)$ \\
\hline Belgium & $9(1)$ & $13(1)$ & $22(2)$ \\
\hline Brazil & $32(9)$ & $16(3)$ & $48(12)$ \\
\hline Canada & $0(0)$ & $8(0)$ & $8(0)$ \\
\hline Chile & $0(1)$ & $5(1)$ & $5(2)$ \\
\hline China & 299 (13) & $47(4)$ & 346 (17) \\
\hline Colombia & $15(3)$ & $6(1)$ & $21(4)$ \\
\hline Denmark & $16(1)$ & $10(1)$ & $26(2)$ \\
\hline Estonia & $2(0)$ & $6(1)$ & $8(1)$ \\
\hline Finland & $30(0)$ & $0(0)$ & $30(0)$ \\
\hline France & $103(4)$ & $122(6)$ & 225 (10) \\
\hline Germany & 87 (1) & $154(4)$ & $241(5)$ \\
\hline Greece & 59 (19) & $15(3)$ & $74(22)$ \\
\hline Hong Kong & $41(3)$ & $111(12)$ & $152(15)$ \\
\hline Hungary & $0(0)$ & $6(0)$ & $6(0)$ \\
\hline India & $17(2)$ & $12(0)$ & $29(2)$ \\
\hline Indonesia & $84(4)$ & $44(2)$ & $128(6)$ \\
\hline Italy & $55(5)$ & $93(2)$ & $148(7)$ \\
\hline Japan & $421(21)$ & $380(28)$ & 801 (49) \\
\hline Korea & 191 (19) & 191 (13) & $382(32)$ \\
\hline Malaysia & $33(1)$ & $81(2)$ & $114(3)$ \\
\hline Mexico & $22(7)$ & $17(5)$ & $39(12)$ \\
\hline Netherlands & $27(1)$ & $19(0)$ & $46(1)$ \\
\hline New Zealand & $9(0)$ & $0(0)$ & $9(0)$ \\
\hline Pakistan & $23(1)$ & $0(0)$ & $23(1)$ \\
\hline Peru & $27(8)$ & $0(0)$ & $27(8)$ \\
\hline Poland & $0(3)$ & $20(4)$ & $20(7)$ \\
\hline Portugal & $8(4)$ & $0(0)$ & $8(4)$ \\
\hline Singapore & $16(0)$ & $37(0)$ & $53(0)$ \\
\hline South Africa & $6(2)$ & $11(2)$ & $17(4)$ \\
\hline Spain & $21(1)$ & $18(2)$ & $39(3)$ \\
\hline Sweden & $9(0)$ & $18(0)$ & $27(0)$ \\
\hline Switzerland & $0(0)$ & 49 (1) & 49 (1) \\
\hline Taiwan & $172(19)$ & 27 (4) & $199(23)$ \\
\hline Thailand & $88(3)$ & $56(3)$ & $144(6)$ \\
\hline Turkey & $70(5)$ & $19(0)$ & $89(5)$ \\
\hline UK & $111(15)$ & 206 (18) & 317 (33) \\
\hline USA & $286(18)$ & $740(30)$ & $1026(48)$ \\
\hline Total in Asia & 1385 (86) & $986(68)$ & $2371(154)$ \\
\hline Total in Europe & $617(62)$ & 777 (43) & $1394(105)$ \\
\hline
\end{tabular}


Table 1 continued

\begin{tabular}{lccc}
\hline Location & Textile & Clothing & Total \\
\hline Total in North America & $286(18)$ & $748(30)$ & $1034(48)$ \\
Total in Middle and & $96(28)$ & $44(10)$ & $140(38)$ \\
$\quad$ South America & & & \\
Total in the Rest of the World & $17(3)$ & $29(4)$ & $46(7)$ \\
Total & $2401(197)$ & $2584(155)$ & $4985(352)$ \\
\hline
\end{tabular}

Table 2 Descriptive statistics of the textile and clothing firms, 1995-2004

\begin{tabular}{lrccc}
\hline Variable & Average & Std. dev. & Min & Max \\
\hline Textiles & & & & \\
Revenues & 343227.800 & 913297.400 & 358.482 & $1.57 \mathrm{e}+07$ \\
Costs of goods sold & 261349.700 & 761170.900 & 250.699 & $1.44 \mathrm{e}+07$ \\
Tangible fixed assets & 157741.000 & 357438.600 & 24.355 & 4971454 \\
Number of employees & 2692.508 & 7416.303 & 2 & 121636 \\
Clothing & & & & \\
Revenues & 348675.200 & 632362.300 & 8.090 & 6237353 \\
Costs of goods sold & 222396.400 & 385193.900 & 10.525 & 3960305 \\
Tangible fixed assets & 78852.430 & 160508.700 & 5.910 & 2214856 \\
Number of employees & 3055.628 & 5813.828 & 2 & 75000 \\
\hline
\end{tabular}

Following Piesse and Thirtle (2000), Wu et al. (2007) and Kapelko and Oude Lansink (2014) ${ }^{9}$, we consider one output and three inputs: costs of goods sold, tangible fixed assets, and number of employees. Output is measured as total sales and other operating revenues. Costs of goods sold involve all costs allocated to production. Tangible fixed assets are measured as the total amount of property, the plant and equipment in monetary terms, and net of depreciation. The number of employees is the annual average of full-time workers. All variables in monetary units (output, costs of goods sold, and tangible fixed assets) are initially expressed in local currencies in current prices ${ }^{10}$. To make these variables comparable across countries, they are divided by the purchasing power parity (PPP) of the local currency to the US dollar. To obtain constant 1995 prices, producer price indices (PPI) are used ${ }^{11}$. Both PPP and PPI are obtained from the World Bank, the International Monetary Fund and the Organization for Economic Co-operation and Development. Table 2 provides the descriptive statistics of the variables for the 1995-2004 time period separately for the textile and clothing companies.

\footnotetext{
${ }^{9}$ Although there are a number of potential problems with the usage of accounting data, this is a very common strategy applied in the efficiency literature to analyze the industrial sectors.

10 We control for monetary events such as currency reforms or the adaptation of the euro by some countries.

11 Detailed price indices adjusted to the type of input/output variable are not available. Only producer price index is available for the majority of countries in the database, hence we apply it here. For these few countries for which producer price index is not available, the Gross Domestic Product (GDP) deflator is used instead.
} 
The Malmquist index is calculated for each firm between two consecutive years of the 1995-2004 time period. Moreover, we perform the computations of the Malmquist index separately for the groups of textile and clothing firms because the production technology differs between these industries. However, we are not able to do the separate estimations for every region analyzed because we do not have enough firms in our database for some regions and some periods of time; the data are particularly limiting for following regions: the Rest of the World, and Middle and South America.

\section{Results}

Table 3 summarizes the geometric means of the Malmquist index and its decomposition separately for the two samples of textile and clothing firms. It should be noted that some of the mixed period linear programs used to compute the Malmquist index may not have a feasible solution. One possible solution to this problem is to omit the observations with infeasible solutions in the computation of averages, which is the strategy we have followed. In line with the recommendation of Briec and Kerstens (2009), we report the infeasibilities that occurred in the empirical application in Table 3. Out of 4985 observations, only 21 observations have an infeasible solution for one of the mixed period linear programs; this represents $0.4 \%$ of the entire sample. Furthermore, Table 3 reports the results of non-parametric test of stochastic dominance (Kolmogorov-Smirnov $(\mathrm{K}-\mathrm{S})$ test statistics) for the differences between textile and clothing industries, which was developed specifically for efficiency analysis by Delgado et al. (2002) ${ }^{12}$.

Table 3 suggests that in the period 1995-2004, the textile and clothing sectors have experienced small average annual productivity growth of 0.3 and $1 \%$, respectively. The productivity increase is largely driven by average annual technological progress of 1.5 and $2 \%$ for the textile and clothing sectors, respectively. The positive contribution of technological progress to productivity growth is partially offset by a deterioration of technical efficiency and scale efficiency. Technical efficiency change and scale efficiency change are slightly more negative in the textile sector $(-0.7$ and $-0.5 \%$, respectively) than in the clothing sector $(-0.6$ and $-0.3 \%$, respectively).

Productivity growth occurred in almost all years; the only exceptions were 2002/2003 and 2003/2004 for the textile sector and 1997/1998 for the clothing sector. Technological progress is also found in almost all years for the textile and clothing sectors. The finding of technological regress in some years suggests that technological change has eliminated some productive options that were previously available for the textile and clothing firms. For example, the increasing liberalization of trade due to the removal of MFA quotas might have forced the companies to undertake additional investments to adapt to the international standards and absorb additional costs with-

\footnotetext{
12 Stochastic dominance refers to the differences between a pair of distributions, as characterized by their cumulative distribution functions. Formally, let us suppose that we have two distributions $A$ and $B$ with cumulative distribution functions $F$ and $G$, respectively. To determine whether both distributions are identical or not, the following hypothesis has to be tested: $H_{0}: F(x)=G(x)$ for all $x \in R$ versus $H_{1}: F(x) \neq G(x)$ for at least one value of $x$. The Kolmogorov-Smirnov two-sided test is used to test this hypothesis. This test is more general than the Wilcoxon as it tests if the entire distribution is different.
} 


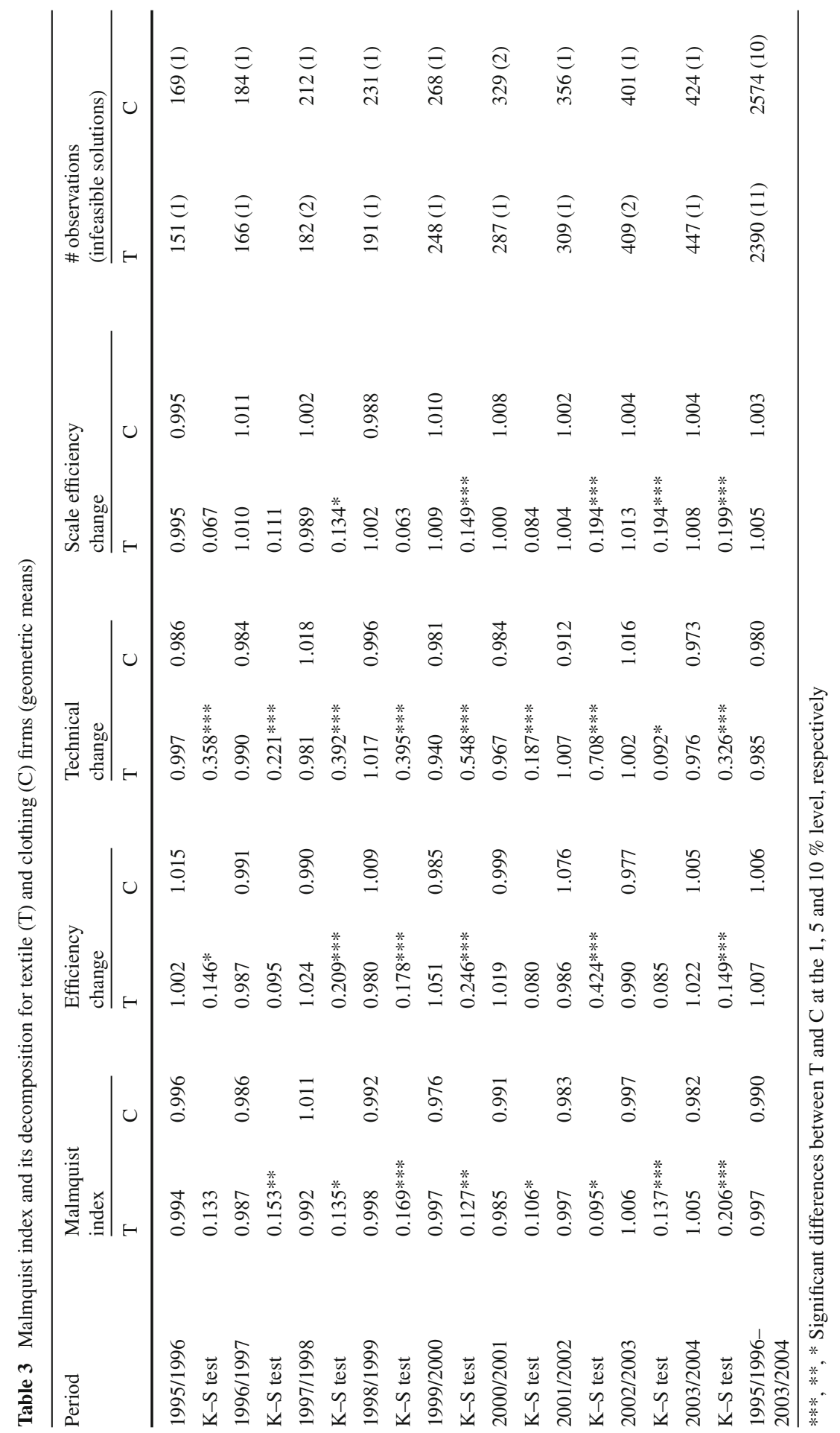


out a direct productivity increasing impact. The decrease of scale efficiency of textile and clothing firms in almost all years indicates that scale of operation has, on average, become less beneficial. Overall, the growth of the gap between efficient and inefficient firms and the technological advances suggest that much of the decrease in technical and scale efficiency can be attributed to the failure of textile and clothing firms to adapt to the technological improvements made by some of their competitors; that is, a few textile and clothing firms are innovators and shift the frontier, while most of the other firms fail to adapt to the technological improvements and fall behind. This result could also explain the large number of exits from the textile and clothing industry in the past decades.

To appropriately compare the differences in indices between textile and clothing firms, we need to look at the results of test of stochastic dominance in Table 3 . These findings indicate that for all periods except for 1995/1996, the null hypothesis of equality of distributions of textile versus clothing firms with regard to the Malmquist index is rejected at all conventional significance levels. Furthermore, there are no significant differences in efficiency change between sectors for three periods of time: 1996/1997, $2000 / 2001$, and 2002/2003. Additionally, there are no significant differences in scale efficiency change across textile and clothing firms: for four periods of time (1995/1996, $1996 / 1997,1998 / 1999$, and 2000/2001), the null hypothesis of equal distributions is not rejected. This result reflects the fact that in the textile and clothing industry, scale efficiency change does not depend on the activity profile. On the other hand, technical change differs across subsectors, as evidenced by the fact that the null hypothesis of equality of distributions is rejected for all periods. As indicated in Table 3, relative to the textile industry, clothing makes more technological improvements in almost all periods of time. These improvements might explain the higher productivity growth observed in this sector for the 1995-2004 period as a whole. All these findings reflect the textile and clothing firms' ability to expand their production possibilities through innovation, while the overall productivity growth demonstrates that the improvement in textile and clothing companies' technology offsets the increases in technical and scale inefficiencies.

Figure 1 illustrates the differences in the distributions of the Malmquist index and efficiency change, technical change, and scale efficiency change between textile and clothing firms. Because of space limitations, the figure displays only some time periods.

The graphs show that the distributions of the Malmquist index and technical change of clothing firms are always below the analogous distributions of textile companies, demonstrating the lower levels of these indices for clothing firms. The graphs suggest that clothing firms made more improvements in productivity and technology than textile companies.

To interpret the changes in the Malmquist index and its components in terms of their statistical significance, we need to analyze the confidence intervals computed by the bootstrap procedure. Table 6 in the Appendix reports the number of firms with significant and insignificant (at the $1 \%$ critical level) growth or decline of the Malmquist index and its components separately for the textile and clothing sectors. As it was outlined before, for these firms for which some of the Malmquist components are infeasible to compute (the infeasibility of mixed period distance functions), the 

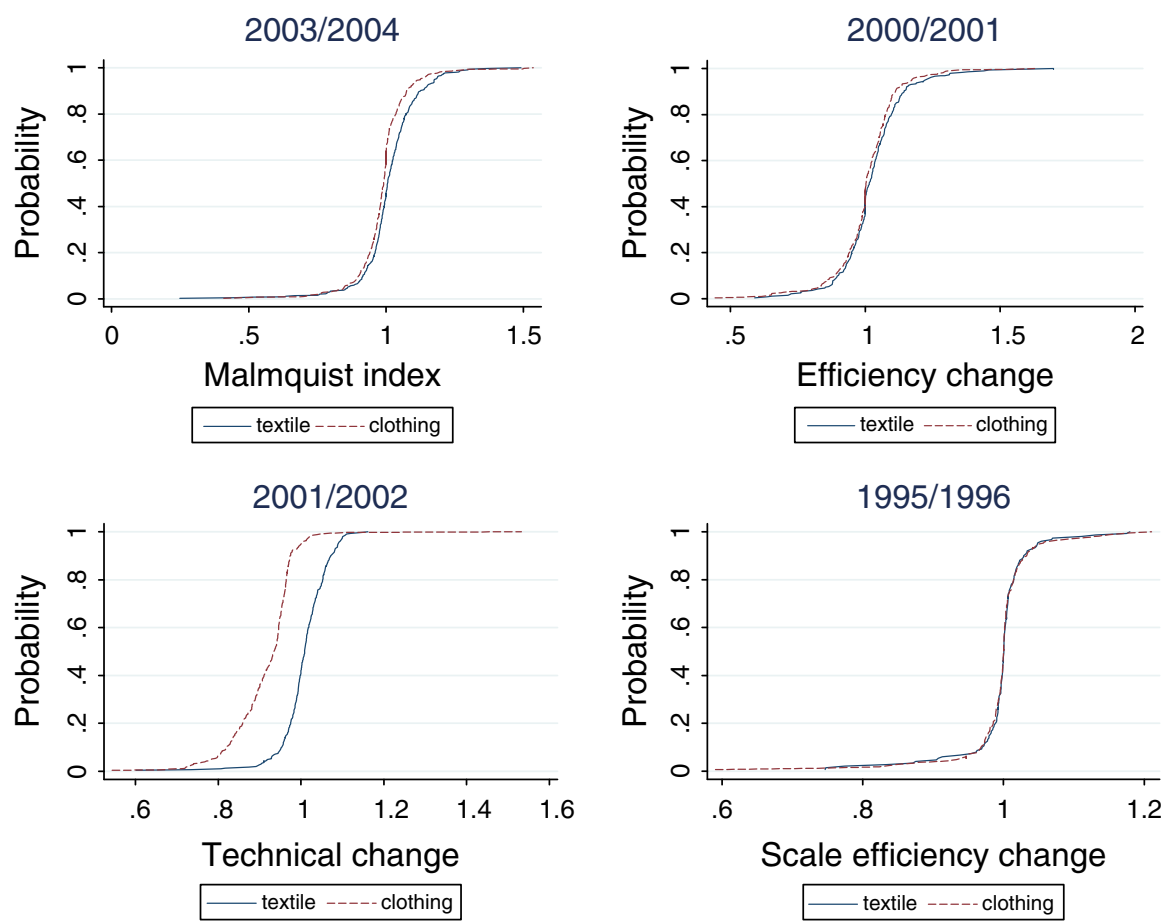

Fig. 1 Differences in indices: textile versus clothing (smooth sample distribution function)

bootstrap's confidence intervals are not estimated as well; therefore, the total numbers reported in Table 6 are equal to the sample size after removing infeasibilities as reported in Table 3. The findings in this table reveal that for the majority of both textile and clothing firms, the changes in productivity, efficiency, technology, and scale are significantly different from 1 at the $1 \%$ significance level. In addition, for a relatively large number of firms, stagnation in productivity and efficiency is found; this result is especially prevalent in the clothing sector. The results in the table show that the number of textile and clothing firms experiencing a significant productivity growth is almost equal to the number of firms experiencing productivity decline. Hence, it is clear that a large number of individual firms have experienced decline, even though Table 3 suggests that productivity has grown on average. The results for technical change in this table also display a larger number of firms experiencing technological progress than regress. Textile and clothing firms experiencing technical efficiency and scale efficiency decline outnumber those experiencing improvement.

\subsection{Productivity change and country position regarding MFA import quotas' removal}

Next, we want to identify the impact of quotas' removal on productivity growth and its components. We compare two groups of firms: the firms in countries which benefited from the removal of quotas and these that did not benefit from the removal, based on the value of country exports before and after the removal of quotas. In particular, the calcu- 
Table 4 Malmquist index and its decomposition (geometric means) and country position regarding the benefits of import quotas' removal

\begin{tabular}{|c|c|c|c|c|c|c|c|c|}
\hline \multirow[t]{2}{*}{ Period } & \multicolumn{2}{|c|}{$\begin{array}{l}\text { Malmquist } \\
\text { index }\end{array}$} & \multicolumn{2}{|l|}{$\begin{array}{l}\text { Efficiency } \\
\text { change }\end{array}$} & \multicolumn{2}{|l|}{$\begin{array}{l}\text { Technical } \\
\text { change }\end{array}$} & \multicolumn{2}{|c|}{$\begin{array}{l}\text { Scale efficiency } \\
\text { change }\end{array}$} \\
\hline & Benefited & $\begin{array}{l}\text { Not } \\
\text { Benefited }\end{array}$ & Benefited & $\begin{array}{l}\text { Not } \\
\text { Benefited }\end{array}$ & Benefited & $\begin{array}{l}\text { Not } \\
\text { Benefited }\end{array}$ & Benefited & $\begin{array}{l}\text { Not } \\
\text { Benefited }\end{array}$ \\
\hline First stage & 1.011 & 0.987 & 1.012 & 0.996 & 0.997 & 0.987 & 1.002 & 1.003 \\
\hline $\mathrm{K}-\mathrm{S}$ test & $0.236 * * *$ & & $0.188 * * *$ & & $0.165^{* *}$ & & 0.075 & \\
\hline Second stage & 0.986 & 0.993 & 1.009 & 1.015 & 0.975 & 0.976 & 1.002 & 1.002 \\
\hline $\mathrm{K}-\mathrm{S}$ test & $0.105^{* * *}$ & & $0.062 *$ & & $0.079 * * *$ & & 0.057 & \\
\hline Third stage & 0.999 & 0.997 & 0.994 & 1.001 & 0.989 & 0.992 & 1.017 & 1.004 \\
\hline $\mathrm{K}-\mathrm{S}$ test & $0.114 * * *$ & & 0.067 & & 0.066 & & $0.202 * * *$ & \\
\hline
\end{tabular}

***, **, * Significant differences between firms that benefited and that did not benefit from the quotas' removal at the 1,5 and $10 \%$ level, respectively

lation compares the mean value of sample country world exports for textile/clothing for the pre-2005 period to that observed in 2005, as published by the World Trade Organization $^{13}$. Furthermore, these analyses are undertaken by separating the dataset into three periods that indicate the progressive removal of quotas as established by the World Trade Organization. The first period ("First stage") ranges from 1995/1996 till $1996 / 1997$, reflecting the integration of products representing not less than $16 \%$ of country 1990 total imports of textile and clothing. The second period ("Second stage") ranges from 1997/1998 till 2001/2002 when not less than further $17 \%$ was integrated. Finally, third period ("Third stage") ranges from 2002/2003 till 2003/2004 reflecting the integration of all remaining textile and clothing products. Table 4 presents the results for Malmquist productivity growth and its components in the first, second, and third phase of removal of quotas, together with K-S test statistics for the differences between firms in countries that benefited and that did not benefit from the elimination of quotas.

A major finding from this analysis is that firms in countries that benefited from the removal of quotas and these that did not benefit respond differently to opening up to trade. Firms that benefited from the quotas' removal improve their performance over time with regard to productivity change, efficiency change, and technical change. It suggests that the increase in export opportunities of firms results in productivity, efficiency, and technology gains. On the contrary, the results reveal the worsening of performance across firms in countries that did not benefit from the quotas' removal after barriers to trade were drastically reduced. In particular, for these firms productivity growth is becoming smaller along the stages of relaxing of quota restrictions. Initial efficiency growth, when still considerable quota restrictions are presented in the market, turns into the efficiency decline in two last stages of opening up to trade.

\footnotetext{
13 For few countries in the sample the data on country exports is obtained from the Organization for Economic Co-operation and Development and EUROSTAT. Unfortunately, the data on the value of exports at firm's level is not available in the datasets which are used in this study. The distinction into countries that benefited and did not benefit from the quotas' removal we find in our calculations is very similar to the findings in other studies, for example to these in Fugazza and Conway (2010).
} 
Although still these firms experience positive technical change, this increase in technical change is becoming smaller when barriers to trade are completely removed. For both types of firms, scale efficiency change remains similar along the stages of quotas' removal. Therefore, the change in trade policy results in the improvement of performance for firms in countries that increase the exports of textile and clothing products and causes the worsening of performance for firms in countries that see the decrease in their value of exports. However, the encountered differences between the productivity growth and its components between firms in countries that benefited and did not benefit from the quotas' removal are not always statistically significant: results of Kolmogorov-Smirnov two-sided test show that this is the case for all stages of quotas' removal with regard to productivity change, for two initial stages for efficiency and technical change and for the last stage for scale efficiency change component.

\subsection{Productivity change in regions}

Table 5 compares the differences in geometric means of the Malmquist index and its components across firms with headquarters ${ }^{14}$ in Asia, Europe, North America, Middle and South America, and the Rest of the World. To test the statistical significance of the differences across regions, a Kruskal-Wallis $(\mathrm{K}-\mathrm{W})$ nonparametric rank test is employed ${ }^{15}$. Table 5 also reports the growth of R\&D intensity in each region between 1995 and 2004. R\&D intensity reflects the R\&D expenditures of the country as a percentage of GDP ${ }^{16}$. Growth in $\mathrm{R} \& \mathrm{D}$ intensity in each region is calculated based on the level of R\&D intensity of countries in the sample as obtained from the World Bank.

Table 5 shows important differences in productivity and its components among regions. Although Table 3 shows that the sample of all textile firms, on average, experienced productivity growth in the period 1995-2004, the results in Table 5 show that the growth only occurred in Asia and North America. Textile firms in Europe, Middle and South America and particularly those in the Rest of the World, experienced a productivity decrease. In all regions, efficiency change made a negative contribution and technical change made a positive contribution to productivity growth. Scale efficiency change made a negative contribution in all regions except the Rest of the World. The results for clothing firms in different regions are in line with the findings for the entire sample of firms, i.e., clothing firms on average experienced a productivity increase in all regions despite the negative contributions of efficiency change and scale efficiency change in most regions. Furthermore, technical progress occurred in all regions for both textile and clothing firms, but is particularly large for textile firms in Asia, and

\footnotetext{
14 Rather than analyzing productivity growth based on the locations of firms' headquarters, it would be interesting to perform this analysis based on the location where most production takes place because it is well known that textile and clothing companies in developed countries are moving the production to less developed countries to benefit from cost advantages and to increase efficiency. Unfortunately, data to do such an analysis are not available for us.

15 The test of stochastic dominance cannot be applied for this purpose as it is designed to compare only two groups of results. The application of the Kruskal-Wallis test to analyze frontier shifts is discussed in Sueyoshi and Aoki 2001.

16 Unfortunately, data on R\&D expenses at firm's level are not available in the datasets that are used in this study.
} 
Table 5 Malmquist index and its decomposition for different regions, 1995-2004 (geometric means)

\begin{tabular}{|c|c|c|c|c|c|c|}
\hline Region & $\begin{array}{l}\text { Malmquist } \\
\text { index }\end{array}$ & $\begin{array}{l}\text { Efficiency } \\
\text { change }\end{array}$ & $\begin{array}{l}\text { Technical } \\
\text { change }\end{array}$ & $\begin{array}{l}\text { Scale } \\
\text { efficiency } \\
\text { change }\end{array}$ & \# observations & $\begin{array}{l}\text { Growth in } \\
\text { R\&D intensity } \\
(1995-2004) \%\end{array}$ \\
\hline \multicolumn{7}{|l|}{ Textiles } \\
\hline Asia & 0.993 & 1.004 & 0.984 & 1.006 & 1385 & 95.213 \\
\hline Europe & 1.006 & 1.015 & 0.987 & 1.004 & 615 & 18.176 \\
\hline North America & 0.995 & 1.005 & 0.987 & 1.002 & 277 & 12.465 \\
\hline $\begin{array}{l}\text { Middle and South } \\
\text { America }\end{array}$ & 1.014 & 1.014 & 0.995 & 1.006 & 96 & 29.964 \\
\hline Rest of the World & 1.019 & 1.040 & 0.986 & 0.993 & 17 & 29.275 \\
\hline $\mathrm{K}-\mathrm{W}$ test & $13.295 * * *$ & $8.486^{*}$ & $15.311 * * *$ & 3.864 & & \\
\hline \multicolumn{7}{|l|}{ Clothing } \\
\hline Asia & 0.984 & 1.004 & 0.978 & 1.002 & 986 & 95.213 \\
\hline Europe & 0.994 & 1.007 & 0.984 & 1.002 & 774 & 18.176 \\
\hline North America & 0.994 & 1.008 & 0.981 & 1.005 & 741 & 12.465 \\
\hline $\begin{array}{l}\text { Middle and South } \\
\text { America }\end{array}$ & 0.983 & 0.998 & 0.964 & 1.022 & 44 & 29.964 \\
\hline Rest of the World & 0.969 & 0.991 & 0.982 & 0.996 & 29 & 29.275 \\
\hline $\mathrm{K}-\mathrm{W}$ test & 7.160 & 2.110 & 1.898 & $8.571 *$ & & \\
\hline
\end{tabular}

$* * *, * *, *$ Significant differences between regions at the 1,5 and $10 \%$ level, respectively

the Rest of the World, and clothing firms in Middle and South America and Asia, suggesting that innovations are mainly introduced in these regions. The data on the growth of R\&D intensity in Table 5 further strengthens this finding as firms in countries located in Asia, Middle and South America and the Rest of the World have the highest growth rates of R\&D intensity between 1995 and 2004 of approximately 95.2, 30 and $29.3 \%$, respectively.

The results of the Kruskal-Wallis test in Table 5 show that the Malmquist index, technical change and efficiency change significantly differ between regions for textile firms, whereas scale efficiency change does not significantly differ. These results for textile firms show that technical change, technical efficiency change and improvement of productivity depend on the geographical location of the firm. Firms in Asia and North America display a better performance than firms in Europe, Middle and South America, and the Rest of the World. For clothing firms, there are significant differences between regions only for scale efficiency change ${ }^{17}$.

To graphically reflect the differences in indices across regions, Fig. 2 shows the distributions of the Malmquist index, efficiency change, technical change and scale efficiency change for some periods of time. Due to space limitations, we only present the graphs of Asia and Europe for textile firms. Figure 2 shows that the Malmquist index and technical change of textile firms differ between these two regions; distributions for

\footnotetext{
17 Although statistically significant differences are found in productivity growth and its decomposition between regions, the reader should keep in mind that within textile and clothing sectors firms are still heterogeneous. A statistically significant difference between regions might reflect differences in the composition of the subgroups.
} 

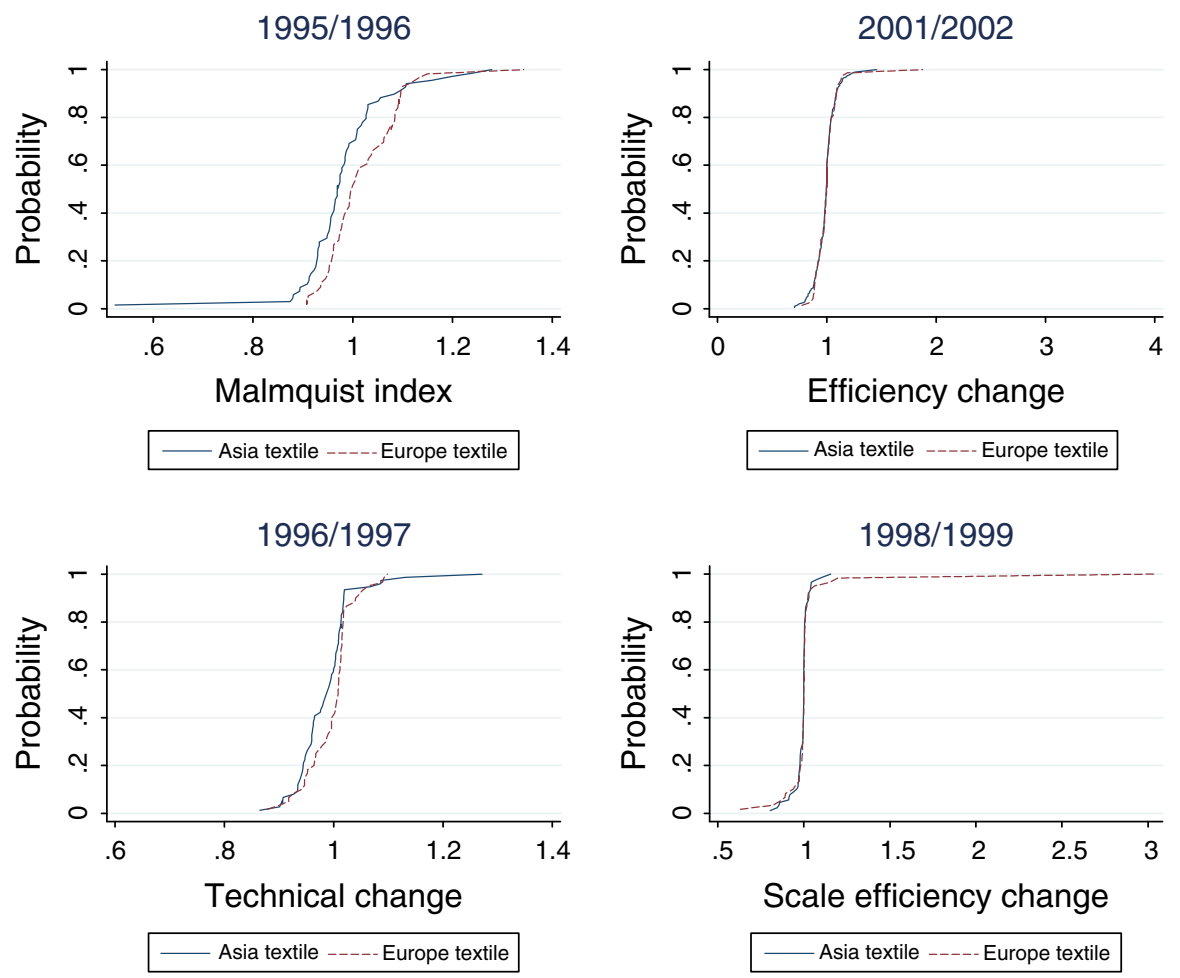

Fig. 2 Differences in indices: Asia versus Europe (smooth sample distribution function)

Asia lie below those for Europe, while distributions for efficiency and scale efficiency change do not markedly differ.

Table 7 in the Appendix reports the bootstrap findings grouped by regional location. This table shows that the majority of textile and clothing firms in all analyzed regions have experienced significant (at the $1 \%$ critical level) changes in the Malmquist index and its components. It is also worthwhile to note that a large number of textile and clothing firms from Asia, Europe and North America stagnated in terms of efficiency; additionally, a large number of North American firms experienced stagnation in terms of overall productivity.

\section{Conclusions and future research}

This paper analyzed productivity change and its decomposition into technical change, technical efficiency change and scale efficiency change of firms in the textile and clothing industry in the context of a gradual removal of MFA quotas on textile and clothing trade. In the face of the new liberalized market, improving productivity is an important condition for competitiveness of the textile and clothing industry. The empirical application used panel data for larger stock exchange listed textile and clothing firms from Asia, Europe, North America, Middle and South America, and the Rest of the World. In the 1995-2004 time period, productivity in the textile and clothing 
industries increased by an average of 0.3 and $1 \%$ per year, respectively. The productivity increase was mainly driven by technical progress, which was partially offset by a decrease in technical efficiency and scale efficiency in both industries. A deeper analysis of productivity growth using the bootstrap method showed that productivity has significantly increased for more than half of the textile and clothing firms. This paper also finds that firms in countries that benefited from the quotas' removal improved their performance, while firms in countries that did not benefit from the quotas' removal worsened their performance in the period of quotas' elimination. Productivity growth and its components also differ depending on a firm's geographic region. Textile firms in North America and Asia experienced productivity growth on average in the period under investigation, whereas productivity declined for firms in Europe, Middle and South America, and the Rest of the World. Clothing firms in all regions experienced productivity growth on average. Another interesting finding is that the firms in regions that achieve the fastest technical change (Asia, Middle and South America, and the Rest of the World), are the ones that have the highest growth in R\&D expenses.

The patterns of productivity, efficiency and technical change observed in this study reflect the rapid adjustments in the production environment in the past decade in the textile and clothing industry. In response to increased competition and new opportunities due to the removal of barriers to trade, the innovative firms have adapted quickly, while others have responded slowly and fallen behind. Of course, we are also cautious in interpreting our results: other forces may have contributed to these changes. To corroborate the findings, future research will need to test whether productivity change is correlated with, for example, the economic conditions of the region/country or the size of firms. Furthermore, in future work, we would need to treat the firms from the Australia and Oceania region separately from those located in Africa. This advance would require more data on companies from these regions. Furthermore, if we are able to collect more data in some regions, future research would allow us to compute the Malmquist index and its components for each region separately; this approach would allow for region-specific production technologies. Future research could also analyze productivity growth and its components of post-quota textile and clothing period to compare it with the current results during the trade reform. With regard to the methodology used, because one of the shortcomings of Malmquist index is that it only measures the local technical change, a promising avenue for future study would be to apply an index that has a TFP interpretation, such as the Hicks-Moorsteen index (O'Donnell 2010, 2012a,b). Another methodological extension for future research, if the data allows for this, would be to model capital as a quasi-fixed input in the technology, e.g., following the proposals of Ouellette and Vierstraete (2004) or De Borger and Kerstens (2000).

Open Access This article is distributed under the terms of the Creative Commons Attribution License which permits any use, distribution, and reproduction in any medium, provided the original author(s) and the source are credited.

\section{Appendix}

See the Tables 6 and 7 
Table 6 Summary of bootstrap results for Malmquist index and its decomposition for textile and clothing subsectors, 1995-2004 (significant differences from 1 at $1 \%$ level)

\begin{tabular}{|c|c|c|c|c|c|c|}
\hline \multirow[t]{2}{*}{ Significance } & \multicolumn{3}{|l|}{ Textiles } & \multicolumn{3}{|l|}{ Clothing } \\
\hline & Growth & Decline & Stagnation & Growth & Decline & Stagnation \\
\hline \multicolumn{7}{|l|}{ Malmquist index } \\
\hline Significant & 1154 & 1141 & & 1297 & 1058 & \\
\hline Not significant & 67 & 1 & 27 & 82 & 1 & 136 \\
\hline \multicolumn{7}{|c|}{ Efficiency change } \\
\hline Significant & 967 & 1147 & & 987 & 1290 & \\
\hline Not significant & 105 & 0 & 171 & 120 & 0 & 177 \\
\hline \multicolumn{7}{|l|}{ Technical change } \\
\hline Significant & 1252 & 1023 & & 1506 & 897 & \\
\hline Not significant & 100 & 14 & 1 & 164 & 0 & 7 \\
\hline \multicolumn{7}{|c|}{ Scale efficiency change } \\
\hline Significant & 1013 & 1271 & & 1113 & 1353 & \\
\hline Not significant & 105 & 0 & 1 & 100 & 1 & 7 \\
\hline
\end{tabular}

Table 7 Significant differences from 1 at $1 \%$ level for the Malmquist index and its components by region

\begin{tabular}{|c|c|c|c|c|c|c|}
\hline \multirow[t]{2}{*}{ Significance } & \multicolumn{3}{|l|}{ Textiles } & \multicolumn{3}{|l|}{ Clothing } \\
\hline & Growth & Decline & Stagnation & Growth & Decline & Stagnation \\
\hline \multicolumn{7}{|l|}{ Asia } \\
\hline \multicolumn{7}{|l|}{ Malmquist index } \\
\hline Significant & 704 & 648 & & 536 & 423 & \\
\hline Not significant & 32 & 1 & & 26 & 0 & 1 \\
\hline \multicolumn{7}{|c|}{ Efficiency change } \\
\hline Significant & 591 & 662 & & 396 & 504 & \\
\hline Not significant & 65 & 0 & 67 & 49 & 0 & 37 \\
\hline \multicolumn{7}{|c|}{ Technical change } \\
\hline Significant & 721 & 594 & & 595 & 330 & \\
\hline Not significant & 64 & 6 & & 61 & 0 & \\
\hline \multicolumn{7}{|c|}{ Scale efficiency change } \\
\hline Significant & 558 & 758 & & 448 & 495 & \\
\hline Not significant & 69 & 0 & & 42 & 1 & \\
\hline \multicolumn{7}{|l|}{ Europe } \\
\hline \multicolumn{7}{|l|}{ Malmquist index } \\
\hline Significant & 280 & 315 & & 412 & 335 & \\
\hline Not significant & 20 & 0 & & 26 & 1 & \\
\hline \multicolumn{7}{|c|}{ Efficiency change } \\
\hline Significant & 221 & 306 & & 310 & 384 & \\
\hline Not significant & 23 & 0 & 65 & 35 & 0 & 45 \\
\hline
\end{tabular}


Table 7 continued

\begin{tabular}{|c|c|c|c|c|c|c|}
\hline \multirow[t]{2}{*}{ Significance } & \multicolumn{3}{|l|}{ Textiles } & \multicolumn{3}{|l|}{ Clothing } \\
\hline & Growth & Decline & Stagnation & Growth & Decline & Stagnation \\
\hline
\end{tabular}

Technical change

Significant 341

18

451

281

Not significant 18

4

42

0

Scale efficiency change

Significant 288

309

401

Not significant

18

0

40

0

North America

Malmquist index

Significant

Not significant

13

Efficiency change

Significant 108

Not significant

12

Technical change

Significant

Not significant

Scale efficiency change

Significant

Not significant

14

Middle and South America

Malmquist index

Significant

37

Not significant

2

Efficiency change

Significant

41

Not significant

5

Technical change

Significant

37

Not significant

4

Scale efficiency change

Significant 50

Not significant

3

Rest of the World

Malmquist index

$\begin{array}{ll}\text { Significant } & 9 \\ \text { Not significant } & 0 \\ \text { Efficiency change } & \\ \text { Significant } & 6 \\ \text { Not significant } & 0\end{array}$

310

28

253

31

413

56

302

17
37

1

1

57

0

49

0

55

0

43

0

8

0

10

0
20

0

14

22

0

5

$31 \quad 10$

30

$16 \quad 27$

10
15
135

7 
Table 7 continued

\begin{tabular}{|c|c|c|c|c|c|c|}
\hline \multirow[t]{2}{*}{ Significance } & \multicolumn{3}{|l|}{ Textiles } & \multicolumn{3}{|l|}{ Clothing } \\
\hline & Growth & Decline & Stagnation & Growth & Decline & Stagnation \\
\hline \multicolumn{7}{|l|}{ Technical change } \\
\hline Significant & 10 & 6 & & 16 & 11 & \\
\hline Not significant & 1 & 0 & & 2 & 0 & \\
\hline \multicolumn{7}{|c|}{ Scale efficiency change } \\
\hline Significant & 7 & 9 & & 14 & 15 & \\
\hline Not significant & 1 & 0 & & 0 & 0 & \\
\hline
\end{tabular}

\section{References}

Ayed-Mouelhi RM, Goaïed M (2003) Efficiency measure from dynamic stochastic production function: application to Tunisian textile, clothing and leather industries. Econom Rev 22(1):93-111

Balk BM (2001) Scale efficiency and productivity change. J Prod Anal 15:159-183

Banker RD, Charnes A, Cooper WW (1984) Some models for estimating technical and scale inefficiencies in data envelopment analysis. Manage Sci 30:1078-1092

Briec W, Kerstens K (2009) Infeasibility and directional distance functions with application to the determinateness of the Luenberger productivity indicator. J Optim Theory Appl 141:55-73

Charnes A, Cooper WW, Rhodes EL (1978) Measuring the efficiency of decision making units. Eur J Oper Res 2:429-444

Chen Y (2003) A non-radial Malmquist productivity index with an illustrative application to Chinese major industries. Int J Prod Econ 83:27-35

Datta A, Christoffersen S (2005) Production costs, scale economies and technical change in U.S. textile and apparel industries. Atlantic Econ J 33:201-213

De Borger BK, Kerstens K (2000) The Malmquist productivity index and plant capacity utilization. Scand J Econ 102(2):303-310

Delgado MA, Fariñas JC, Ruano S (2002) Firm productivity and export markets: a non-parametric approach. J Int Econ 57:397-422

Färe R, Grosskopf S, Lindgren B, Roos P (1992) Productivity change in Swedish pharmacies 1980-1989: a nonparametric Malmquist approach. J Prod Anal 3:85-101

Färe R, Grosskopf S, Norris M, Zhang Z (1994) Productivity growth, technical progress and efficiency change in industrialized countries. Am Econ Rev 84(1):66-83

Färe R, Grosskopf S, Lee W-F (2001) Productivity and technical change: the case of Taiwan. Appl Econ 33:1911-1925

Fried HO, Lovell CAK, Schmidt SS (2008) The measurement of productive efficiency and productivity growth. Oxford University Press, New York

Fugazza M, Conway P (2010) The impact of removal of ATC quotas on international trade in textiles and apparel. Policy Issues in International Trade and Commodities Study Series No 45. http://unctad.org/ en/PublicationsLibrary/itcdtab45_en.pdf. Accessed August 2013

Gitto S, Mancuso P (2012) Bootstrapping the Malmquist indexes for Italian airports. Int J Prod Econ 135:403-411

Goaïed M, Ayed-Mouelhi RB (2000) Efficiency measurement with unbalanced panel data: evidence from Tunisian textile, clothing and leather industries. J Prod Anal 13:249-262

Goncharuk AG (2007) Impact of political changes on industrial efficiency: a case of Ukraine. J Econ Stud 34(4):324-340

Grifell-Tatjé E, Lovell CAK (1999) A generalized Malmquist productivity index. TOP 7(1):81-101

Guan J, Chen K (2010) Modeling macro-R\&D production frontier performance: an application to Chinese province-level R\&D. Scientometrics 82:165-173

Joshi RN, Singh SP (2010) Estimation of total factor productivity in the Indian garment industry. JFMM 14(1):145-160 
Kapelko M, Oude Lansink A (2014) Examining the relation between intangible assets and technical efficiency in the international textile and clothing industry. J Text I 105(5):491-501

Kong X, Marks RE, Wan GH (1999) Technical efficiency, technological change and total factor productivity growth in Chinese state-owned enterprises in the early 1990s. Asian Econ J 13(3):267-281

Kumar M, Basu P (2008) Perspectives of productivity growth in Indian food industry: a data envelopment analysis. Int J Prod Perform Manag 57(7):503-522

Leung H-M (1998) Productivity of Singapore's manufacturing sector: an industry level non-parametric study. Asia Pac J Manage 15:19-31

Lovell CAK (2003) The decomposition of Malmquist productivity indexes. J Prod Anal 20:437-458

Mahadevan R (2002) A DEA approach to understanding the productivity growth of Malaysia's manufacturing industries. Asia Pac J Manage 19:587-600

Mahlberg B, Url T (2010) Single Market effects on productivity in the German insurance industry. J Bank Financ 34:1540-1548

Margono H, Sharma SC (2006) Efficiency and productivity analyses of Indonesian manufacturing industries. J Asian Econ 17:979-995

Mittelhauser M (1997) Employment trends in textiles and apparel, 1973-2005. Mon Labour Rev 120(8):2435

Nordås HK (2004) The global textile and clothing industry post the agreement on textiles and clothing. World Trade Organization discussion paper no 5. http://www.wto.org/english/res_e/booksp_e/ discussion_papers5_e.pdf. Accessed June 2012

O’Donnell CJ (2010) Measuring and decomposing agricultural productivity and profitability change. Aust J Agric Resour Econ 54(4):527-560

O’Donnell CJ (2012a) An aggregate quantity-price framework for measuring and decomposing productivity and profitability change. J Prod Anal 38(3):255-272

O'Donnell CJ (2012) Nonparametric estimates of the components of productivity and profitability change in U.S. agriculture. Am J Agric Econ 94(4):873-890

Ondrich J, Ruggiero J (2002) Outlier detection in data envelopment analysis: An analysis of jackknifing. J Oper Res Soc 53(3):342-346

Ouellette P, Vierstraete V (2004) Technological change and efficiency in the presence of quasi-fixed inputs: a DEA application to the hospital sector. Eur J Oper Res 154(3):755-763

Owen G (2001) Globalisation in textiles: corporate strategy and competitive advantage. The third annual Pasold lecture delivered at the London School of Economics. http://www.lse.ac.uk/collections/MES/ pdf/pasold.pdf. Accessed June 2012

Pastor JT, Lovell CAK (2007) Circularity of the Malmquist productivity index. Econ Theory 33:591-599

Piesse J, Thirtle C (2000) A stochastic frontier approach to firm level efficiency, technological change and productivity during early transition in Hungary. J Comp Econ 28:473-501

Ray SC, Desli E (1997) Productivity growth, technical progress and efficiency change in industrialized countries: comment. Am Econ Rev 87(5):1033-1039

Shephard RW (1970) Theory of cost and production functions. Princeton University Press, Princeton

Simar L, Wilson PW (1999) Estimating and bootstrapping Malmquist indices. Eur J Oper Res 115:459-471

Simar L, Wilson PW (2000) A general methodology for bootstrapping in non-parametric frontier models. J Appl Stat 27(6):779-802

Simar L (2003) Detecting outliers in frontier models: a simple approach. J Prod Anal 20(3):391-424

Stengg W (2001) The textile and clothing industry in the EU. A survey. European commission enterprise paper no 2. http://ec.europa.eu/enterprise/library/enterprise-papers/pdf/enterprise_paper_02_2001.pdf. Accessed June 2012

Sueyoshi T, Aoki S (2001) A use of a nonparametric statistic for DEA frontier shift: the Kruskal and Wallis rank test. Omega Int J Manag Sci 29(1):1-18

Taymaz E, Saatçi G (1997) Technical change and efficiency in Turkish manufacturing industries. J Prod Anal 8:461-475

Timmer ChP (1971) Using a probabilistic frontier production function to measure technical efficiency. J Polit Econ 79(4):776-794

Wadud M (2007) Sources of productivity growth in Australian textile and clothing firms. Aust Econ Pap 46(3):254-281

Wilson PW (1993) Detecting outliers in deterministic nonparametric frontier models with multiple outputs. J Bus Econ Stat 11(3):319-323 
Wilson PW (2008) FEAR: a software package for frontier efficiency analysis with R. Socio Econ Plan Sci 42(4):247-254

World Bank (2005) World Development Indicators. World Bank, New York.

Wu ZB, Yeung G, Mok V, Han Z (2007) Firm-specific knowledge and technical efficiency of watch and clock manufacturing firms in China. Int J Prod Econ 107:317-332

Yeung G, Mok V (2004) Does WTO accession matter for the Chinese textile and clothing industry? Camb J Econ 28:937-954

Zofio JL (2007) Malmquist productivity index decompositions: a unifying framework. Appl Econ 39:23712387 